\title{
DO INSTITUTO DA TRANSMISSÃO DO DIREITO DE SUCEDER DO ARTIGO 2058॰ DO CÓDIGO CIVIL
}

\section{Eva Dias Costa ${ }^{1}$}

\section{Resumo}

O Código Civil prevê no artigo 2058. ${ }^{\circ}$ a possibilidade de o direito de aceitar ou repudiar a herança se transmitir para os herdeiros do sucessível que, chamado (i.e., que, à data da abertura da sucessão, reunisse os pressupostos da vocação sucessória (a sobrevivência ao de cuius, a capacidade sucessória e a titularidade da designação prevalente), tenha, entretanto, falecido sem a ter aceitado ou repudiado.

A epígrafe do artigo é tão simplesmente "transmissão". A doutrina tem chamado a este instituto, direito de transmissão, transmissão do direito de suceder ou transmissão do direito de aceitar ou repudiar a herança.

Rejeitamos à partida a primeira: não se trata, na verdade, de uma forma especial de suceder, antes da aplicação normal das regras da transmissibilidade mortis causa dos direitos. Não há direito de transmissão, mas transmissão de um direito.

Mas, de que direito? É na escolha entre as duas restantes expressões reside a razão de ser desta reflexão: os herdeiros do sucessível que, chamado, morre sem aceitar ou aceitar a herança vêm transmitido para eles o direito hereditário que cabia a este segundo de cuius na herança do primeiro, sucedendo a este por essa via, ou apenas se transmite para eles o ius delationis, o direito de aceitar ou repudiar a herança que, neste caso, integrará o património do segundo de cuius a quem - e só a quem - estes sucedem?

É a esta questão, que é no fundo a da natureza e efeitos deste instituto (com as consequências, civis e tributárias, que podem ser retiradas) que procuraremos responder.

Palavras-chave: Sucessão mortis causa, herança, aceitação e repúdio, transmissão, ius delationis, representação, acrescer.

O artigo 2058. do Código Civil Português, sob a epígrafe "transmissão", prevê que, se o sucessível chamado à herança falecer sem a haver aceitado ou repudiado se transmite aos seus herdeiros o direito de aceitar ou repudiar, e que a transmissão só se verifica se os herdeiros aceitarem a herança do falecido, os que não os impede de repudiar, querendo, a herança a que este fora chamado.

Esta figura não se confunde com a do direito de representação dos artigos 2039. e ss., tão pouco com o direito de acrescer previsto nos artigos 2301. . e ss. do Código. É, no entanto, como procuraremos explanar, uma representação, mas no sentido que lhe atribui o artigo 258. ${ }^{\circ}$ do Código Civil, o de praticar atos em nome alheio.

\footnotetext{
${ }^{1}$ Professora Auxiliar do Departamento de Direito. Investigadora Integrada do Instituto Jurídico Portucalense (Fundação Ciência e Tecnologia).Editora Adjunta da Revista Jurídica Portucalense. E-mail: eva@upt.pt
} 
A quaestio iuris é esta: alguém é chamado à herança de outrem e reúne todos os pressupostos da vocação, a titularidade da designação prevalente, a sobrevivência ao de cuius e a capacidade sucessória ${ }^{2}$. Para que efetivamente suceda é necessário apenas que aceite a herança, expressa ou tacitamente ${ }^{3}$, retroagindo os efeitos da aceitação, por força da particular magia das ficções jurídicas, à data da abertura da sucessão 4 .

A alternativa, i.e., o repúdio da herança (que tem de ser expresso, consentido pelo cônjuge do chamado casado num regime de comunhão e que também retroage à data da abertura da sucessão ${ }^{5}$ ), acionará ou o direito de representação ou o direito de acrescer ou, ainda, na sucessão voluntária, poderá importar o chamamento do substituto designado.

Acontece que, na situação de que curamos, o chamado, por sua vez, também morreu. Se, no momento da morte, já havia aceitado ou repudiado a herança a que fora chamado, o problema está resolvido: ou a sua quotaparte na herança já integra o seu património, que agora também é hereditário e ao qual serão chamados aqueles que a lei ou o negócio jurídico tiverem prescrito, ou a repudiou, e nem ele nem os seus sucessíveis têm quanto a ela qualquer pretensão ${ }^{6}$.

O problema surge quando, chamado, morreu sem ter expressado validamente a sua vontade quanto à aceitação ou ao repúdio da herança e é aqui que o artigo 2058. do CC, determina que este direito se transmite aos seus herdeiros.

A questão, colocada muito simplesmente, é esta: o que se transmite? O direito de suceder ao primeiro de cuius ou o direito de, em nome do segundo de cuius, aceitar ou repudiar a herança do primeiro?

Na primeira solução, quem sucede ao primeiro de cuius são os herdeiros do segundo, que terão relativamente ao primeiro vocação sucessória, ainda que indireta, derivada, subsequente ou anómala ${ }^{7}$.

Na segunda solução - que claramente preferimos - apenas se transmite para os herdeiros do segundo de cuius o direito de, em nome e representação dele, aceitar ou repudiar a herança do primeiro de cuius.

Aceitando-a, aquela quota hereditária integra a herança deste e, repudiando-a, deixa o segundo de cuius de ter - ainda que postumamente - qualquer pretensão à herança, funcionando o direito de representação, a substituição ou o direito de acrescer, conforme seja o caso nos termos da lei e da vontade que o primeiro de cuius tenha validamente expressado.

\footnotetext{
${ }^{2}$ A doutrina é unânime quanto a estes pressupostos ou requisitos, ditos gerais ou comuns, da vocação sucessória. Vide CAMPOS, Lições de Direito da Família e das Sucessões, Almedina, 2001, pp. 505 a 525, CORTE-REAL, Curso de Direito das Sucessões, Quid Juris, 2012, pp. 192 a 219, ASCENSÃO, Direito Civil - Sucessões, Coimbra Editora, 2000, pp. 121 a 153, FERNANDES, Lições de Direito das Sucessões, Quid Juris, 2012, pp.155 a 183.

${ }^{3}$ Cf. o artigo 2056. ${ }^{\circ}$ do CC.

${ }^{4}$ Nos termos do disposto no n. ${ }^{\circ}$ do artigo $2052 .^{\circ}$.

${ }^{5} \mathrm{Cf}$. os artigos $16833^{\circ}, 2062 .^{\circ}$ e $2063 .^{\circ}$ do CC.

${ }^{6}$ Isto, sem prejuízo da possibilidade de sub-rogação dos credores do repudiante, prevista no artigo 2067. do CC.

${ }^{7}$ Voltaremos a este ponto.
} 
Nesta hipótese há, como dizíamos acima, representação mas não na aceção sucessória ${ }^{8}$, antes na aceção do artigo 258. ${ }^{\circ}$ do CC: o negócio jurídico realizado pelos herdeiros produz os seus efeitos na esfera jurídica do representado, o segundo de cuius. Na verdade, em resultado desta viagem no tempo só possível em ficção literária e jurídica, a aceitação que é expressa pelos herdeiros do segundo de cuius produz efeitos na esfera deste desde a abertura da sucessão, momento em que, recorde-se, ele ainda estava vivo e, portanto, reunia os pressupostos da vocação.

A escolha parece-nos simples e quer a letra da lei quer o enquadramento do sistema sucessório apontam, no nosso entender, para esta segunda solução. Que não deixa, aceitamos, de colocar problemas que tentaremos, se não resolver, ao menos deixar enunciados.

A doutrina portuguesa, no tratamento escasso que tem feito da figura, parece favorecer aquela primeira hipótese, a de que há uma vocação dos herdeiros do segundo de cuius relativamente à herança do primeiro.

Com a possível exceção de ASCENSÃO que, não sendo perentório nem exaustivo no tratamento da figura, sempre diz que o direito de suceder é adquirido pelo segundo de cuius e passa, por via do artigo 2058. ${ }^{\circ}$,.$^{\circ}$ 1, aos herdeiros dele. Os herdeiros recebem, pois, o direito de suceder que, para o Autor, consiste justamente no direito de aceitar ou repudiar, conduzindo assim a resultados muito diversos daqueles que resultam do direito de representação 9 .

CORTE-REAL, que é criticado por ASCENSÃO ${ }^{10}$ e por FERNANDES ${ }^{11}$, considera que na transmissão do direito de suceder os herdeiros do transmitente têm uma dupla vocação: direta, relativamente a este $\mathrm{e}$, indireta, face ao primeiro de cuius ${ }^{12}$.

SOUSA ${ }^{13}$ também trata exiguamente a figura, sobretudo quando a distingue claramente a figura do direito de representação e recusa a tese da vocação indireta, embora entenda que não se trata de uma representação legal por sucessão ${ }^{14}$. Conclui que há no direito de transmissão uma segunda vocação a favor dos

\footnotetext{
${ }^{8}$ Em que o representante atua em nome e por conta própria e os atos jurídicos que pratique se repercutem na sua própria esfera. Vide CAMPOS, Lições ..., p. 533.

${ }^{9}$ Cf. Direito Civil - Sucessões, pp. 154 a 156.

${ }^{10}$ Ibidem.

${ }^{11}$ Lições de Direito das Sucessões, pp. 287 a 289. O Autor rejeita a ideia de CORTE-REAL de que há no direito de suceder uma vocação indireta dos transmissários, mas não é claro quanto aos efeitos da figura. Parece, no entanto, aderir àquela que consideramos que é a melhor doutrina quando afirma que estão aqui em causa duas sucessões diferentes e que o direito de aceitar e repudiar a herança do primeiro é mais um dos direitos que integram a herança do segundo de cuius.

${ }^{12}$ Curso de Direito das Sucessões, pp. 233 a 235.

${ }^{13}$ Nas suas Lições de Direito das Sucessões, Vol. I, 2000, Coimbra Editora, pp. 331 e ss..

${ }^{14} \mathrm{O}$ Autor identifica esta representação legal por sucessão nos casos de sucessão na posse, na legitimidade dos herdeiros para prosseguir em ações de filiação e de estado e considera que esta representação não tem lugar no jus transmissionis. O Autor não explica, mas será porque considera que o direito de aceitar ou repudiar se transmitiu aos herdeiros do primeiro chamado, que o exercem em nome próprio, ainda que com consequências na esfera jurídica deste atento o efeito retroativo da aceitação e do repúdio. É o que parece decorrer também da frase que usa na p. 352: “( . . ) enquanto os herdeiros do sucessível que faleceu sem ter aceitado ou repudiado a sucessão não exercerem o seu direito de aceitação ou repúdio ( ... ) ”. Nosso enfatizado. No Vol II das
} 
herdeiros do chamado que morreu sem aceitar ou repudiar a herança.

Há, portanto, entende ${ }^{15}$, dois fenómenos sucessórios e que os pressupostos da vocação sucessória têm de se verificar no primeiro chamado face ao de cuius e, depois, no(s) segundo(s) chamado(s) face ao primeiro, mas já não face ao de cuius - a que, de facto, dizemos nós, não sucedem.

CAMPOS também não desenvolve o ponto nas suas Lições ${ }^{16}$, mas, embora refira que é o direito de aceitar que se transmite hereditariamente, entende que com a aceitação há uma transmissão patrimonial direta do primeiro de cuius para os transmissários, herdeiros do segundo de cuius, o que impõe que estes sejam capazes também em relação àquele.

Percebe-se a opção de um ponto de vista tributário: a ser assim, há apenas uma aquisição, um único facto tributário, enquanto na solução que continuamos a preferir há, reconhecemos, face à atual redação da lei fiscal (designadamente, no momento em que escrevemos, do código do imposto de selo), duas aquisições que configuram outros tantos factos tributários e poderão determinar, dependendo das normas de incidência pessoais e reais, duas situações de sujeição a imposto ${ }^{17}$. Abordaremos este problema mais adiante.

Não é só entre nós que a figura ${ }^{18}$ suscita dúvidas.

A doutrina do país vizinho, por exemplo, também se debate com a natureza e efeitos da successio iure transmissionis que foi vertida ao artigo 1006 do Código Civil espanhol: "Por muerte del heredero sin aceptar ni repudiar la herencia pasará a los suyos el mismo derecho que él tenía."

Para ALBALADEJO, com apoio no texto da lei, o beneficiário da transmissão é verdadeiramente herdeiro - direto - do primeiro de cuius, i.e., é sucessor do transmitente ou primeiro chamado no ius delationis. Sucede no mesmo direito que cabia ao transmitente e é sucessor do primeiro de cuius de forma direta e não através da sua posição na herança do transmitente do ius delationis. Daí que o Autor proponha a ideia da exigência de dupla capacidade: em relação ao transmitente e ao primeiro de cuius ${ }^{19}$.

\footnotetext{
Lições, 2002, Coimbra Editora, o Autor também refere, a pp. 16 e ss. e 66, que o direito de aceitar ou repudiar a sucessão é "hereditável", transmissível por morte.

${ }^{15}$ Idem, ibidem.

${ }^{16}$ Páginas 533 e $534,578$.

${ }^{17}$ Atento o efeito meramente declarativo da partilha.

${ }^{18}$ Encontrámo-la no artigo 775 do Code Civil francês de 2006, que determina que o direito de aceitar ou repudiar é transmitido aos herdeiros do chamado que morre sem o exercer e que cada um dos herdeiros deste pode exercer o seu direito separadamente, cada um relativamente à sua parte.

Bem assim, no artigo 479 do Codice Civile italiano que, sob a epígrafe Trasmissione del diritto di accettazione determina que "Se il chiamato all'eredità muore senza averla accettata, il diritto di accettarla si trasmette agli eredi.Se questi non sono d'accordo per accettare o rinunziare, colui che accetta l'eredità acquista tutti i diritti e soggiace a tutti i pesi ereditari, mentre vi rimane estraneo chi ha rinunziato.La rinunzia all'eredità propria del trasmittente include rinunzia all'eredità che al medesimo è devoluta.". As redações da lei francesa e da lei italiana favorecem prima facie a tese da vocação sucessória dos herdeiros do segundo relativamente ao primeiro.

${ }^{19}$ Curso Derecho Civil, Tomo V, Sucesiones, 1989, Bosch.
} 
No extremo oposto, SASTRE ${ }^{20}$ e BERDEJO ${ }^{21}$ consideram que o transmissário é herdeiro do transmitente, jamais do primeiro de cuius, pelo que tem de ter capacidade unicamente relativamente àquele. A aceitação do transmissário tem como consequência que o transmitente herde do primeiro de cuius e só através daquele, porque integra a herança daquele, é que chega à esfera jurídica do transmissário.

Também ÁLVAREZ e PARTE ${ }^{22}$ oferecem argumentos interessantes a favor desta segunda posição. Para estes Autores, é muito claro que o herdeiro do primeiro de cuius é o transmitente, não o transmissário, porque, dizem, o que se transmite é tão só o conteúdo da delatio, nunca a titularidade do ius delationis, que permanecerá localizada no transmitente, por ser inseparável da sua pessoa, intransmissível.

O objeto da transmissão é, assim, um simples título legitimador para que o transmissário exercite o conteúdo de uma vocação-delação da qual o transmitente continua a ser o titular, ou seja, que é o exercício e não a titularidade que se transmite. $\mathrm{O}$ mesmo é dizer, como defendemos supra, que o transmissário exerce o direito em nome do transmitente e com efeitos diretos na esfera jurídica deste ${ }^{23}$.

Segundo os Autores ${ }^{24}$, é o próprio jogo da eficácia retroativa da aceitação que permite afirmar que o transmitente aceitou a herança e adquiriu a qualidade de herdeiro em vida. E acrescentam um argumento de peso: se o transmissário sucedesse ao primeiro causante, seria deste herdeiro pessoa designada ao segundo ou por ele escolhida pelo segundo, à margem quer da vontade do primeiro, quer da designação legal, mesmo imperativa, relativa à herança deste, quer das regras do direito de representação.

No Brasil, a figura está prevista na primeira parte do artigo 1.809 do Código Civil:

Falecendo o herdeiro antes de declarar se aceita a herança, o poder de aceitar passa-the aos herdeiros, a menos que se trate de vocação adstrita a uma condição suspensiva, ainda não verificada. Parágrafo único: Os chamados à sucessão do herdeiro falecido antes da aceitação, desde que concordem em receber a segunda herança, poderão aceitar ou renunciar a primeira..

Para FARIA ${ }^{25}$ a figura é totalmente distinta da do direito de representação. Trata-se, na transmissão, de uma sucessão dentro de outra: os herdeiros de um herdeiro pós-morto ao autor da herança, que ainda não declarou se aceita a herança, habilitam-se na parte que lhe couber no monte hereditário.

Também para GOMES ${ }^{26}$ a transmissão não se confunde com a representação: "Sucede por esse direito, quando, depois da abertura da sucessão, falece o herdeiro sem ter aceito ou repudiado a herança, a ele transmitida

\footnotetext{
20 "Estudios de Derecho Privado", Revista de Derecho Privado, 1948.

${ }^{21}$ Elementos de Derecho Civil V, Derecho de Sucesiones, 2009, Dykinson.

22 "Sobre el carácter meramente instrumental de la transmisión del ius delationis (ex artículo 1006 del Código Civil). La posición jurídica del transmitente y del transmisario." Anuario de Derecho Civil, 1996, pp. 1541-1597.

${ }^{23}$ No entanto, entendem, quanto à capacidade, que o transmissário, para poder exercer o ius delationis, tem de ter capacidade quer quanto ao transmitente quer quanto ao primeiro de cuius.

${ }^{24}$ Ibidem.

${ }^{25}$ Direito das Sucessões: Teoria e Prática, 2003, Forense, p. 53.

${ }^{26}$ Sucessões, 2015, Forense.
} 
desde a sua abertura.". GONÇALVES ${ }^{27}$, no mesmo sentido, distingue a representação da transmissão considerando que há naquela vocação indireta e, nesta, dupla vocação sucessória.

No mesmo sentido vai a lição de OLIVEIRA ${ }^{28}$ : o herdeiro que falece antes de aceitar a herança morre na posse de um direito - o de aceitar ou renunciar a herança. Este direito, que já faz parte do seu património, é, como os demais direitos, transmissível por sucessão hereditária. Por isso, o herdeiro que falece no período de delação, isto é, antes de declarar se aceita a herança, transmite-a, integralmente, aos seus próprios herdeiros e é assim que se opera a aquisição por transmissão hereditária.

Na prática, devem os descendentes do herdeiro que faleceu posteriormente habilitar-se nos autos de inventário, declarando que aceitam a herança por direito de transmissão na medida em que o presumido herdeiro falecido posteriormente ao autor da herança não praticou qualquer ato que demonstrasse a aceitação da herança.

Não descurando a fortíssima influência romana no nosso direito sucessório moderno, fomos em busca das origens da figura.

JUSTO apresenta-a no capítulo que dedica à delatio que define como o chamamento e o consequente direito de aceitar ou repudiar a herança que é deferida ou oferecida, i.e., a faculdade de adquirir a herança ${ }^{29}$.

A regra quanto à delação era, na época clássica, de intransmissibilidade, antes ou depois da aceitação, entre vivos ou mortis causa: hereditas delatia, nondum adquisita, non transmittitur ad heredes. Todavia, sofreu tantas atenuações e derrogações que à época justinianeia já estava invertida e era de transmissibilidade ${ }^{30}$.

Tanto JUSTO como IGLESIAS ${ }^{31}$ identificam várias importantes exceções à regra clássica que ocorriam quando um herdeiro falecesse antes de aceitar a herança, designadas por transmissiones.

Entre elas, a transmissio ex capite in integrum restitutionis, que tinha lugar a favor do herdeiro daquele que, chamado, renunciara à herança por certas causas ou falecera sem a aceitar, que podia assim destruir os efeitos da renúncia ou afastar a omissão e aceitar a herança.

Também a transmissio iure patrio, concedida a favor do pater do filiusfamilias infans que morreu antes de aceitar a herança: a herança deferida ao filius era adquirida pelo paterfamilias ${ }^{32}$.

Ainda a transmissio ex iure sanguinis ou Theodosiana, que ocorria a favor dos herdeiros de um herdeiro voluntário que tivesse falecido antes da abertura do testamento; a transmissio Iustiniana, na qual a faculdade de aceitar se transmitia para os herdeiros do herdeiro legítimo ou legitimário que falecesse sem aceitar a herança antes de decorrido um ano sobre a delação; e a concessão do actiones utiles aos herdeiros do herdeiro que faleceu sem

\footnotetext{
${ }^{27}$ Direito Civil Brasileiro, Volume 7, Direito das Sucessões, 2014, Saraiva.

${ }^{28}$ Tratado de Direito das Sucessões, 1987, Freitas Bastos.

29 “Direito Privado Romano - V", Stvdia Ivridica 97, 2009, Coimbra Editora, pp. 49 e ss..

${ }^{30}$ Idem, ibidem, e ainda IGLESIAS, Derecho Romano, 2002, Ariel, pp. 378 e 379.

${ }^{31}$ Nas obras e páginas que vimos citando.

${ }^{32}$ Ainda JUSTO, op. cit., p. 55, e IGLESIAS, op. cit. P. 378.
} 
poder aceitar a herança por não se poder abrir o testamento ou desconhecer a delação.

Repare-se que já o direito romano não trata estes casos como cessões, antes como transmissiones e, se não é claro o que realmente se passava nestas, é certo que, nos casos de in iure cessio hereditatis, que era nula antes da aceitação, mas válida depois desta ${ }^{33}$, o cessionário era herdeiro como se tivesse sido chamado à herança, na vez do cedente ${ }^{34}$.

Nada disso, porém, responde de forma suficientemente clara ao problema: há, quanto ao direito hereditário em causa, duas vocações sucessórias, ou apenas uma?

A resposta tem consequências importantes, desde logo, quanto à capacidade sucessória dos titulares do direito de suceder: se têm vocação sucessória quanto ao primeiro, têm de relativamente a este ser capazes de suceder; se não a têm, só relativamente ao segundo de cuius têm de ser capazes, mas já não relativamente ao primeiro, Será, neste caso, o exato oposto do que sucede na representação: os representantes têm de ser capazes quanto ao de cuius, ainda que não o sejam quanto àquele que representam.

Do ponto de vista tributário, já falado, a tese que defendemos (a de que há duas vocações sucessórias em sujeitos diferentes e duas transmissões sucessivas) tem como consequência imediata a verificação de dois factos tributários que ocorrem em esferas diversas.

$\mathrm{Na}$ verdade, a ser assim, na primeira transmissão o facto ocorre na esfera do primeiro de cuius, sendo o imposto dívida da herança, e os herdeiros do segundo, ainda que sejam devedores do imposto, não são os contribuintes em sentido próprio e respondem com o património da herança ou com a medida da sua quota na herança desta, depois da partilha.

Na segunda transmissão, o facto tributário já ocorre na esfera dos herdeiros do segundo de cuius, que são, agora sim, os contribuintes, que respondem com o seu património.

No primeiro caso, a medida da capacidade contributiva é a do valor da quota do chamado falecido sem aceitar ou repudiar na herança do de cuius; no segundo caso, é o do valor da quota dos segundos chamados na herança do primeiro chamado. Passa-se, para efeitos tributários, exatamente o mesmo que se passaria se o primeiro chamado tivesse vivido apenas para declarar a sua aceitação e falecesse no fôlego seguinte. Num caso e noutro, o primeiro chamado não viveria para gozar a quota hereditária adquirida, que logo a seguir se transmitira para os seus herdeiros ${ }^{35}$.

Sucede, porém, que os herdeiros do segundo, sendo os contribuintes em sentido estrito na segunda transmissão, mas não o sendo na primeira transmissão (que lhes transmite a responsabilidade pelo pagamento por via sucessória e com a autonomia patrimonial que decorre do direito das sucessões), são, em ambos os casos, os

\footnotetext{
${ }^{33}$ JUSTO, op. cit. pp. 53 e 54.

${ }^{34}$ IGLESIAS, op. cit. p. 378.

${ }^{35}$ Sendo certo que neste caso poderia, caso o primeiro chamado tivesse tido ainda fôlego, deixada em legado.
} 
sujeitos passivos de duas obrigações tributárias que, do ponto de vista deles, decorre de um único a acréscimo patrimonial e revela uma única capacidade contributiva.

Nesse sentido, sem prejuízo de não estar preenchido o critério relativo à identidade dos contribuintes, é defensável que se gera uma situação de dupla tributação jurídica ou económica. Tributa-se, em resultado de uma ficção jurídica de retroatividade, o mesmo acréscimo patrimonial o que, fazendo sentido em direito civil, já não faz qualquer para efeitos tributários e poderá configurar violação do princípio da capacidade contributiva ${ }^{36}$.

O sistema jurídico tributário tem preocupações de neutralidade neste género de situações e introduz cláusulas de eliminação da dupla tributação que, no entanto, para este caso concreto, não estão existem. A solução técnica poderia ser passar pela dedução à coleta (gerada pela segunda transmissão) do imposto pago pela herança na primeira transmissão (a que post mortem ocorreu a favor do primeiro chamado).

As questões não se circunscrevem, porém à área tributária.

Designadamente, há ainda que dar solução ao seguinte problema: o que acontece quando os herdeiros do primeiro chamado não concordam quanto à aceitação ou ao repúdio, ou quando algum ou alguns deles não se pronunciam? Terá o cabeça-de-casal poderes, terá que se pedir a intervenção do Tribunal para dirimir o litígio ou funcionará entre eles, por exemplo, o direito de acrescer? Em que medida poderá funcionar o direito de representação a favor daquele que, tendo aceitado a herança do primeiro chamado, não pode ou não quer aceitar a herança do de cuius? E finalmente, quais são, num caso e noutro, em relação à herança e aos respetivos credores, os direitos e obrigações dos herdeiros do primeiro chamado?

A resposta a cada uma destas perguntas está diretamente relacionada com a resposta que se der à que anteriormente colocamos: o que se transmite, o direito à herança ou meramente o direito de aceitar ou repudiar? O mesmo é perguntar: os transmissários têm vocação sucessória - seja ela indireta, subsequente, anómala relativamente ao de cuius ou é o primeiro chamado que a conserva; na esfera de quem se produzem em primeira linha os efeitos da aceitação ou do repúdio?

Tentemos perceber qual foi a intenção do nosso legislador quando assentou na redação no artigo 2058. do Código Civil.

No anteprojeto da Parte do novo Código Civil relativa ao Direito das Sucessões, de TELLES ${ }^{37}$, os parágrafos 1 e 2 do artigo $31 .^{\circ}$ correspondem, sem diferenças de revelo, aos atuais números 1 e 2 do artigo 2058. . Existe, todavia, neste artigo um terceiro parágrafo, que não foi vertido à redação definitiva do Código e que rezava: " $33^{\circ}$ - Se só algum ou alguns dos herdeiros aceitam a herança deferida ao falecido, e os demais a repudiam, os primeiros adquirem-na integralmente.".

\footnotetext{
${ }^{36}$ Vide, a propósito da dupla tributação jurídica e económica, NABAIS, Direito Fiscal, pp. 233 e 234.

37 "Direito das Sucessões. Anteprojeto de Uma Parte do Futuro Código Civil Português", Boletim do Ministério da Justiça, n. . 54, 1956, pp. 33 e 34.
} 
Duas importâncias consequências se extraem deste parágrafo quanto à intenção de TELLES - que é, ao menos em parte, a mens legislatoris: que os herdeiros não têm de exercer em conjunto e em igual sentido o direito de aceitar ou repudiar ${ }^{38}$ e que a parte dos que repudiam parece acrescer ${ }^{39}$ aos restantes, que a adquirem - a herança deferida ao falecido) em nome próprio.

Ou seja, no anteprojeto de TELLES, é a vocação sucessória, não o direito de aceitar ou repudiar, que se transmite aos herdeiros do primeiro chamado e na esfera daqueles, não deste, que a aquisição se concretiza. $\mathrm{O}$ mesmo é dizer, só há uma vocação sucessória ${ }^{40}$, que passa do primeiro chamado que faleceu sem a aceitar ou repudiar, para os herdeiros deste.

Nesta conceção, não são muito diferentes os efeitos da transmissão do direito de aceitação do artigo 31 . $^{\circ}$ e da representação, cujo conceito é oferecido no artigo 14.o: "Dá-se representação quando a lei chama os descendentes de uma pessoa a suceder como ela sucederia, nos casos em que essa pessoa não pode ou não quer aceitar a sucessão", mas com diferentes beneficiários.

Dissemos já que entendemos que uma tal solução não respeita a lógica do sistema.

As Atas da Comissão não lançam qualquer luz sobre a intenção do Autor do Anteprojeto nem explicam a razão pela qual acabou por não vingar o dito terceiro parágrafo e o artigo acabou por ter a redação que, sem qualquer alteração, conserva até aos dias de hoje.

A redação do Código de Seabra não era, aliás, mais clara do que a que veio a ser a do Código de 1966. A figura era tratada, como é hoje, no contexto da aceitação e do repúdio da herança e lia-se artigo 2032. que "se o herdeiro falecer sem aceitar ou repudiar a herança passará a seus herdeiros o direito de aceitar ou repudiar" e, no artigo 2033. ${ }^{\circ}$, que "o herdeiro que tiver aceitado a herança do falecido, pode repudiar a herança que este não tivesse aceitado ao tempo da sua morte; mas o repúdio da herança do falecido trará consigo o repúdio de toda e qualquer herança que lhe fosse conferida”.

No artigo 2033. transparece a ideia de que os herdeiros do primeiro chamado têm vocação sucessória relativamente ao de cuius: de outra forma, se uns aceitassem, mas outros repudiassem, a herança do primeiro chamado, seria como se o primeiro chamado repudiasse a herança do de cuius.

Não é essa, naturalmente, a ideia do legislador: a consequência do repúdio é a de que os restantes acrescerão na parte que ao repudiante cabia, uma solução que corresponde, parece-nos, à solução proposta no malogrado parágrafo terceiro do artigo $31 .^{\circ}$ do Anteprojeto.

No número 2 do artigo 2058. do atual Código já cabe - e dificilmente caberia no Código de Seabra - a

\footnotetext{
${ }^{38}$ Em exceção à proposta que consta do artigo 65. o Anteprojeto: “ ( ... ) os direitos relativos à herança só poderão ser exercidos conjuntamente por todos os herdeiros ( ... .).

${ }^{39} \mathrm{O}$ direito de acrescer vem tratado nos artigos $307 .^{\circ}$ a $310 .^{\circ}$ do Anteprojeto.

${ }^{40}$ Indireta, subsequente, anómala ...?
} 
solução que preferimos, tendo em conta que só os que aceitam, a herança do primeiro chamado são herdeiros dele e, como tal, só assim adquirem o direito de aceitar o repudiar a herança do de cuius, sem que aceitação de uma implique obrigatoriedade de aceitação da outra. Do que decorre que o repúdio de uma não pode implicar o repúdio da outra: o repúdio da herança do primeiro chamado tem como única consequência que não se transmite para o sucessível repudiante o direito de aceitar ou repudiar a herança do de cuius.

O direito à herança do de cuius, caso seja aceite, vai integrar o património do primeiro chamado desde a abertura da sucessão daquele, por força da retroatividade da aceitação, e na medida em que o primeiro chamado que faleceu sem a haver aceitado ou repudiado dele não terá tido oportunidade de dele dispor ${ }^{41}$.

Em conclusão, não cremos que se justifique no nosso sistema jurídico sucessório a coexistência de dois institutos - o direito de representação e o direito de transmissão - que teriam sensivelmente os mesmos efeitos, mas com beneficiários tão díspares. No primeiro caso, os descendentes do filho ou do irmão do autor da sucessão, o que se compreende de uma perspetiva romanista, familiar, de sucessão por estirpes, e no segundo, os herdeiros de qualquer herdeiro (legitimário, legítimo ou até voluntário ${ }^{42}$ ).

É que no caso em que funciona o direito de representação, já não se verificava, no momento da abertura da sucessão, um dos pressupostos da vocação sucessória daquele que seria o titular da designação prevalente (a sobrevivência ${ }^{43}$ ) e, para conservar o direito na estirpe, o legislador chama os descendentes deste, que sucedem por via indireta ao primeiro e por isso têm que ter em relação a ele capacidade sucessória.

No caso em que se opera a transmissão do direito de suceder, os pressupostos da vocação estavam todos verificados no momento da abertura da sucessão e faltou apenas a aceitação para que se consolidasse a aquisição sucessória (ou o repúdio, para que fossem chamados os representantes, substitutos ou os titulares do direito de acrescer).

O chamado já não pode exercer esse direito, porque morreu, e são os seus herdeiros quem, em nome dele, o exerce, à semelhança do que acontece quanto a alguns direitos de personalidade, aos direitos morais ligados à propriedade intelectual e a algumas ações de estado, casos em que os herdeiros os defendem ou prosseguem em nome e representação do falecido e não exercendo um direito próprio.

É esta, no nosso entender, a solução compatível com a ideia de que a verificação dos pressupostos da vocação sucessória deve ser concomitante com a abertura da sucessão e a de que os efeitos da aceitação e do

\footnotetext{
${ }^{41}$ Tendo em conta que hoje (cf. artigo 2057. o), como na vigência do Código de Seabra (cf. artigo 2029. o), a alienação da herança a título oneroso ou a título gratuito a favor de apenas alguns dos beneficiários do direito de representação, da substituição ou do acrescer não implica a sua aceitação.

${ }^{42}$ Isto, a delimitarmos a figura ao herdeiro. Se a estendermos ao legatário, os beneficiários seriam os herdeiros de qualquer sucessível.

${ }^{43}$ A comparação só faz sentido, claro, quando falamos de morte do chamado. O alcance do direito de representação e o do direito de transmissão não é o mesmo, na medida em que o direito de representação a favor dos descendentes, na sucessão legal, também nasce da falta de capacidade sucessória do titular da designação prevalente que sobreviveu ao de cuius.
} 
repúdio e mesmo de uma eventual declaração de indignidade retroagem a este momento.

\title{
THE INSTITUTE OF THE TRANSMISSION OF THE RIGHT TO SUCCEED IN ARTICLE 2058. OF THE PORTUGUESE CIVIL CODE
}

\begin{abstract}
Article 2058 of the Portuguese Civil Code allows for the possibility of transmission of the right to accept or reject an inheritance to be transmitted to the heirs of one who is called but dies without having expressed their decision. The article in question names the institute simply transmission, but different authors have called it the right of transmission, transmission of the right to succeed and transmission of the right to accept or reject an inheritance. The distinction is not irrelevant, we believe. In fact, whereas the right of transmission is a somewhat neutral expression, one that is in line with the parallel institutes of the right of representation and the right to accrue, the choice between the second and the third expressions contends with the very nature of the institute. The heirs of one who is called to succeed (because he has the prevalent designation, has survived the de cuius, and is capable), but dies without accepting or rejecting this inheritance have the right to succeed to the first de cuius or are they only given the right to accept or reject in his name?

The two cases are very different, the law is not clear on this, and each solution involves a diverse regimen, both in terms of civil rights and with regards to taxation.

We will therefore try to answer this question, the question of the true nature of the institute.
\end{abstract}

Keywords: Inheritance, ius delationis, acceptance, rejection, representation, right to accrue

\section{BIBLIOGRAFIA}

ÁLVAREZ, J. L., \& PARTE, C. C. (10 - 12 de 1996). Sobre el carácter meramente instrumental de la transmisión del ius delationis (ex artículo 1006 del Código Civil). La posición jurídica del transmitente y del transmisario. Anuario de Derecho Civil, Tomo XLIX, Fascículo IV, pp. pp. 1541-1597.

ALBALADEJO, M. (1989). Curso Derecho Civil, Tomo V, Sucesiones. Barcelona, Espanha: Bosch.

ASCENSÃO, J. d. (2000). Direito Civil - Sucessões (5.a, Revista ed.). Coimbra, Portugal: Coimbra Editora.

BARROSO, M. M. (1983). Questões práticas de Direito das Sucessões e Imposto sobre as Sucessões e Doações (3. a atualizada ed.). Braga, Portugal.

BERDEJO, J. L. (2009). Elementos de Derecho Civil V, Derecho de Sucesiones (4ª Ed. ed.). Barcelona: Dykinson.

CAMPOS, D. L. (2001). Lições de Direito da Família e das Sucessões (2.a Edição Revista e Atualizada ed.). Portugal: Almedina.

CAMPOS, D. L., \& CAMPOS, M. M. (2016). Lições de Direito da Família. Lisboa, Portugal: Almedina. 
CORTE-REAL, C. P. (2012). Curso de Direito das Sucessões. Lisboa, Portugal: Quid Juris.

FARIA, M. R. (2003). Direito das Sucessões: Teoria e Prática. Rio de Janeiro: Forense.

FERNANDES, L. A. (2012). Lições de Direito das Sucessões (4.a edição (revista e atualizada) ed.). Lisboa, Portugal: Quid Juris.

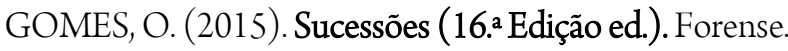

GONÇALVES, C. R. (2014). Direito Civil Brasileiro, Volume 7, Direito das Sucessões (8.. Edição ed.). Saraiva.

IGLESIAS, J. (2002). Derecho Romano (14.a, revista ed.). Barcelona, Espanha: Editorial Ariel.

JUSTO, A. S. (2009). Direito Privado Romano - V (Direito das Sucessões e Doações). Stvdia Ivridica - Boletim da Faculdade de Direito da Universidade de Coimbra, 97, p. Separata.

OLIVEIRA, A. V. (1987). Tratado de Direito das Sucessões (5.a edição, revista e atualizada ed.). Freitas Bastos.

SASTRE, R. M. (1948). Estudios de Derecho Privado. Revista de Derecho Privado, Volumen II, p. pp. 294 a 301.

SILVA, G. d. (1962). Direito das Sucessões. Coimbra, Portugal: Associação Académica da Faculdade de Direito.

SOUSA, R. C. (2000). Lições de Direito das Sucessões (4.. Renovada ed, Vol. I). Coimbra, Portugal: Coimbra Editora.

$\overline{\text { Editora. }}$

(2002). Lições de Direito das Sucessões (3.a. Renovada ed., Vol. II). Coimbra, Portugal: Coimbra

TELLES, I. G. (Março de 1956). Direito das Sucessões. Anteprojeto de uma Parte do Futuro Código Civil Português. Boletim do Ministério da Justiça, n. ${ }^{\circ}$ 54, pp. pp. 19-136.

(2004). Sucessões - Parte Geral. Coimbra, Portugal: Coimbra Editora.

TOBEÑAS, C. (2010). Derecho Civil Español Común y Foral, Tomo VI, Derecho de Sucesiones, Vol. I, La sucesión en general. La sucesión Testamentaria (1 ${ }^{a}$ parte), (9a Edición revisada y puesta al día por José María Castán Vázquez y José Batista Montero- Ríos ed.). Madrid, Espanha: Editorial Reus.

Vv. (Fevereiro de 1964). Atas da Comissão Revisora do Anteprojeto do Direito das Sucessões do Futuro Código Civil Português. Boletim do Ministério da Justiça, n. ${ }^{\circ}$ 133, p.pp.57 a 255.

Trabalho enviado em 28 de setembro de 2016.

Aceito em 16 de abril de 2017. 